\author{
Ahmet Erdem ${ }^{1}$ \\ Department of Educational Sciences, Faculty of Education, \\ Gaziosmanpaşa University, Tokat, Turkey \\ Fuad Bakioğlu \\ Department of Educational Sciences, Faculty of Education, \\ Karamanoglu Mehmetbey University, Karaman, Turkey
}

Original scientific paper

UDC: 37.013 .78

DOI: $10.5937 /$ IstrPed2002169E

\title{
GENDER ROLES AND DATING VIOLENCE: A MEDIATOR ROLE OF MORAL DISENGAGEMENT
}

\begin{abstract}
The aim of this study was to investigate the mediator role of moral disengagement in the relationship between gender roles and dating violence. Participants were 425 university students [310 (72.9\%) female, 115 (27.1\%) male, Mage $=20.68$ years, $\mathrm{SD}=2.21$ ] who completed questionnaires package involving the Gender Roles Attitudes Scale, the Attitudes toward Dating Violence Scales, and the Moral Disengagement Scale. The data were analyzed using structural equation modeling. A bootstrapping analysis was conducted in order to determine any indirect effects. The results showed that gender roles predicted moral disengagement and dating violence negatively, and that moral disengagement predicted dating violence positively. It was further found that the structural equation model that proposed that gender roles had a direct and an indirect effect through moral disengagement on dating violence was confirmed. The results of the study were discussed in the light of relevant literature, and suggestions for future studies were made.
\end{abstract}

Keywords: Gender Roles, Daring Violence, Moral disengagement, University Students.

\section{Introduction}

There are many social, economic, religious and cultural reasons behind the background of the dating violence that has become a social problem (Angelone, Mitchell, \& Lucente, 2012). Dating violence has a few types such as physical violence (slapping, hitting, kicking, etc.), psychological violence (humiliation, pressuring, nicknaming, etc.), sexual violence (sexual abuse, unwanted sexual behavior, sexual pressure, etc.), and stalking (threatening and unwanted attention, etc.) (Niolon et al., 2017; Yumusak \& Sahin, 2014). Moreover, cyber dating violence which occurs online is considered within this scope in recent years (Erdem, Tunc, \& Erdem, 2018; Morelli et al., 2018).

When the prevalence of dating violence is examined, it is seen that one in four women and one in nine men were exposed to physical, psychological, sexual or stalking dating violence at least once (Breiding, Chen, \& Black, 2014). In addition, approximately $10 \%$ of the students were exposed to at least one of the dating violence behaviors in the form of slapping, shock or

\footnotetext{
1 drahmeterdem@gmail.com

²uadpdr@gmail.com
} 
physical injury. (CDC, 2014). Women are more likely to be exposed to dating violence than men.

The determinants of dating violence include poor education, low family support and a family with a history of gender and race violence, stress, anxiety, adherence to gender roles, violence in the previous relationship, substance abuse, and communication skills (Caetano et al., 2000; Jakupcak, Lisak, \& Roemer, 2002; Niolon et al., 2017). Attitude towards gender role which has an important place among these factors (Reyes et al., 2016) is the beliefs held by individuals regarding the roles of men and women, boys and girls (McHugh \& Frieze 1997). Gender roles are considered as either traditional or egalitarian. Traditional gender roles are those that nourish the patriarchal structure, allow men to be at the forefront, and fix the woman to the boundaries set by society (Turan et al., 2011). Egalitarian gender roles mean that women and men have equal responsibilities in career choice, social and cultural activities, domestic responsibilities, child care and upbringing (King \& King, 1990). On the other hand, it is observed that individuals with traditional roles have a perception that the last word in the decision should belong to the man and that women should be passive and play a home-care role (Amato \& Booth, 1995). According to traditional gender norms, sexually offensive men are less concerned with gender equality (Bouffard, 2010). In a study on 120 undergraduates using "Traditional/Egalitarian Sex Role Inventory", while there was a significant relationship between traditional gender roles and violence, it was concluded that women became victims more often (Willis, Hallinan, \& Melby, 1996). In another study, men with traditional gender roles were more likely to blame women who were victims of violence (Hillier \& Foddy, 1993). In a study conducted with adolescents, it was concluded that people with traditional gender roles became victims of violence more often (Hilton, Harris, \& Rice, 2003). In relevant studies, it was found that men with traditional gender roles have higher levels of acceptance of dating violence than women (Berkel, Vandiver, \& Bahner, 2004; Hillier \& Foddy, 1993; Hilton, Harris \& Rice, 2003). Similarly, other studies have found that individuals with sexist attitudes towards women have higher acceptance levels of dating violence (Brown, Sumner, \& Nocera, 2002; Follingstad et al., 1988; Forbes et al., 2006; Taylor \& Sorenson, 2005). As a result, it is seen that there is a relationship between the violence of men against their partners and the traditional gender roles, as well as the relationship between the victim status of women and their traditional gender roles. Individuals with traditional gender roles may have a more affirmative perception of the violence in the dating relationship while individuals with an egalitarian perception will not be able to tolerate the violence; moreover, those with egalitarian perception have lower rates of being the victim of violence than those with traditional gender roles.

In the literature, the moral agency theory which Bandura discusses within the scope of the Social Cognitive Learning Theory comes to the fore as one of the strongest theories trying to explain the violent behavior (Bandura, 1991; Bandura et al., 1996). In moral agency theory, it is emphasized that thought and behavior cannot be separated. In addition, behavior is considered along with cognitive processes. In this theory, certain moral standards are taken into account in the evaluation of the individual's behavior. The individual develops his/her own moral standards when he/she adopts and exhibits the behaviors he/she accepts internally (Bandura, 1991; 2002). Moral standards enable individuals to experience social and personal satisfaction by acting as determinants of their behavior. Behaviors that do not comply with moral standards of the individual correspond to personal and negative sanctions such as selfcriticism and self-condemnation. The individual who behaves outside the moral standards cannot self-control his/her behavior by experiencing the feelings of guilt and regret, and 
experiences a moral disengagement. In this case, the mechanisms of moral disengagement come into play and allow the cognitive restructuring of the behaviors of individuals that do not comply with the moral standards (Bandura, 1991; Bandura et al., 1996). Among the moral disengagement mechanisms, advantageous comparison, euphemistic language, and moral justification are used to restructure the cognition so as to make harmful behavior seem morally acceptable. Diffusion of responsibility and displacement of responsibility cause the denial of individuals' responsibility of behaviors that do not comply with the moral standards by making the responsibility uncertain. Disregard or distortion of consequences makes the consequences of individuals' negative behaviors unworthy and minimize their effects. In Dehumanization and attribution of blame processes, victim is no longer viewed as a person and is regarded as responsible for the negative behavior and its consequences (Bandura, 1990).

Moral disengagement provides evidence in explaining negative behaviors and understanding the underlying causes (Hyde, Shaw, \& Moilanen, 2010). The literature shows that age, education, socio-economic level and religiosity have no effect in the moral disengagement of individuals. (Bandura, Barbaranelli, \& Caprara, 1996). On the other hand, although there is no study focusing on the relationship between dating violence and moral disengagement, a study focusing on the relationship between moral disengagement and antisocial behavior has shown that moral disintegration was a predictor of antisocial behavior (Hyde, Shaw, \& Moilanen, 2010). In other studies, it was found that moral disengagement was positively associated with aggression, violence, bullying, and antisocial behaviors (Bandura, Caprara, \& Zsolnai, 2000; Bandura et al., 1996, 2001; Caprara et al., 1996; Gini, 2006; Menesini et al., 2003; Paciello et al., 2008). Moreover, the longitudinal studies evidenced the positive relationship between moral disengagement and violence (Bandura et al., 2001; Elliott \& Rhinehart, 1995; Pepler et al., 2008). Individuals with moral disengagement can cause physical and psychological harm to both themselves and others (Bandura, 2002, 2017, Paciello et al., 2008). All this information suggests that moral disengagement behavior may be related to the dating behavior.

Moral disengagement and gender roles are seen as related variables. Individuals with traditional gender roles adapt their misbehavior to their own moral standards. Thus, the behaviors such as humiliation, marginalization, violence, and dehumanization behaviors towards his/her partner become not morally wrong for him/her (Bandura, 1990). The individual considers the judgment on his/her partner as a right. Therefore, it can be stated that individuals with egalitarian gender roles do not already have a goal to put pressure on their partners, but that individuals with traditional gender roles can refer to various ways to ensure that their partner is subject to him/her to maintain his or her authority. Within this scope, the purpose of this study was to investigate the mediating role of moral disengagement in the relationship between gender roles and dating violence. The hypothesized model regarding this purpose can be seen in Figure 1. 


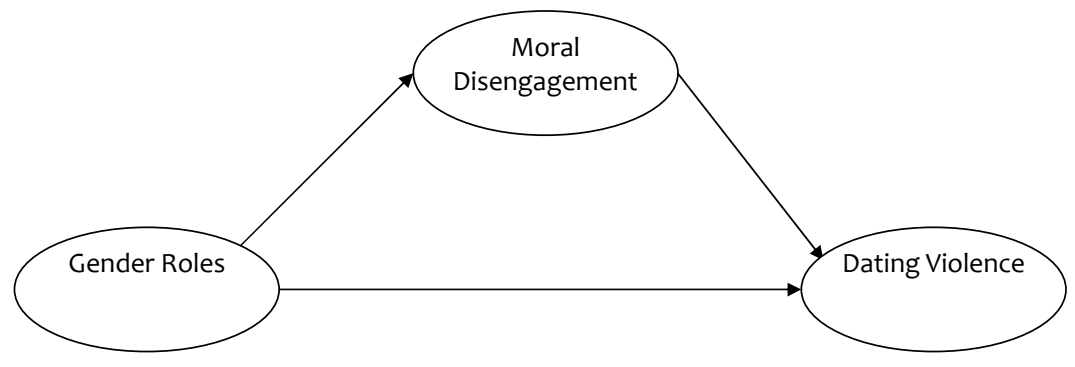

Figure 1. The hypothesized structural model

\section{Method}

\section{Participants}

In this study, convenience sampling method was used. The sample of 425 volunteered university students from university in the northwest part of Turkey was recruited between October and December 2018. The mean age of the participants was 20.68 years (Standard Deviation $=2.21)$ with a range from 18 to 33 years. Of these, $72.9 \%(\mathrm{~N}=310)$ were female and $27.1 \%(\mathrm{~N}=115)$ were male.

\section{Measures}

The data for this study were collected using the Gender Role Attitudes Scale, the Attitudes towards Dating Violence Scale and the Moral Disengagement Scale. Detailed information concerning these measures is presented below.

Gender Roles Attitude Scale: Gender role attitude was measured with the Gender Roles Attitudes Scale (GRAS) developed by García-Cueto and his colleagues (2015). The GRAS is a self-report questionnaire with 15 items. Items were rated on 5-point Likert scale from 1 (totally disagree) to 5 (totally agree). Items include statements such as "People should be treated equally, regardless of their sex". The total score of the GRAS was the sum of the 15 items, with the range from 15 to 75, a higher score indicates an egalitarian gender roles attitude level. GRAS was translated into Turkish by Bakioğlu and Türküm (in press). The Turkish versions of the GRAS have good construct validity $\left(\chi^{2} / \mathrm{df}=2.44\right.$, RMSEA $=.07, \mathrm{GFI}=.90, \mathrm{AGFI}=.87, \mathrm{CFI}=$ $.96, \mathrm{IFI}=.96, \mathrm{NNFI}=.96$ and SRMR $=.05)$ and internal reliability (Cronbach's $\alpha=.88)$ and testretest reliability coefficients $(\alpha=.77)$. In this study, the GRAS also exhibited excellent reliability (Cronbach's $\alpha=.82$ ).

The Attitudes towards Dating Violence Scales: Dating Violence attitude was measured with the The Attitudes toward Dating Violence Scales (ATDVS) developed by Price and Byers (1988). These scales measure attitudes toward use of psychological, physical and sexual dating violence, respectively, by boys and by girls. The scales were named as Attitudes towards Male Psychological Dating Violence Scale (15 item), Attitudes towards Male Physical Dating Violence Scale (12 item), Attitudes towards Female Psychological Dating Violence Scale (11 item), and Attitudes towards Female Physical Dating Violence Scale (12 item). The ATDVS is a self-report questionnaire with 50 items. Items were rated on 5-point Likert scale from 1 (totally disagree) to 5 (totally agree). Items include statements such as "Girls have a right to 
tell their boyfriend how to dress", "It is O.K. for a girl to slap her boyfriend if he deserves it." ATDVS was translated into Turkish by Yumuşak and Şahin (2014). The Turkish versions of the ATDVS have good construct validity (for Attitudes Towards Male Psychological Dating Violence Scale: $\mathrm{RMSEA}=.11, \mathrm{GFI}=.84, \mathrm{AGFI}=.79, \mathrm{CFI}=.84, \mathrm{IFI}=.84, \mathrm{NNFI}=.81$, SRMR $=.08$; of Attitudes towards Male Physical Dating Violence Scale: $\mathrm{RMSEA}=.11, \mathrm{GFI}=.89, \mathrm{AGFI}=.84, \mathrm{CFI}=$ $.94, \mathrm{IFI}=.94, \mathrm{NNFI}=.92, \mathrm{SRMR}=.06$; for Attitudes towards Female Psychological Dating Violence Scale: $\mathrm{RMSEA}=.12, \mathrm{GFI}=.88, \mathrm{AGFI}=.82, \mathrm{CFI}=.83, \mathrm{IFI}=.83, \mathrm{NNFI}=.79$, SRMR = .08; of Attitudes towards Female Physical Dating Violence Scale: RMSEA $=.12, \mathrm{GFI}=.88, \mathrm{AGFI}=.82$, $\mathrm{CFI}=.90, \mathrm{IFI}=.90, \mathrm{NNFI}=.87, \mathrm{SRMR}=.07$ ) and internal reliability (Cronbach's $\alpha=$ ranging from .75 to .87 ). In this study, the ATDVS also exhibited excellent reliability (Cronbach's $a=$ ranging from .78 to .83$)$.

Moral Disengagement Scale: Moral disengagement was measured with the Moral Disengagement Scale (MDS) developed by Moore and his colleagues (2011). The MDS is a selfreport questionnaire with 7 items. Items were rated on a 5-point Likert scale from 1(totally disagree) to 5 (totally agree). Items include statements such as "It is okay to spread rumors to defend those you care about". The total score of the Turkish-MDS was the sum of the 7 items, with the range from 7 to 35 , a higher score indicates a moral disengagement level. MDS was translated into Turkish by Erbaş and Perçin (2017). The Turkish version of the MDS have good construct validity $\left(\chi^{2} / \mathrm{df}=.72, \mathrm{RMSEA}=.00, \mathrm{GFI}=.99, \mathrm{AGFI}=.98, \mathrm{CFI}=1.00\right.$ and $\left.\mathrm{SRMR}=.03\right)$ and internal reliability (Cronbach's $a=.78$ ). In this study, the MDS also exhibited good reliability (Cronbach's $\alpha=.74)$.

\section{Procedure}

The participants completed paper-and-pencil questionnaires in a classroom environment. In the data collection stage of the research, the assessment tools were prepared as a leaflet and distributed to students in a classroom environment, all of whom had volunteered to participate in the research. Before each assessment application, the researchers introduced themselves and explained the importance and purpose of the research. In addition, the researchers told the participants that there would be no individual evaluation and no requirement for identity information and that the results would be used for scientific purposes only. The participants were allowed to answer the questionnaires at their own pace and typically took about 20 minutes to complete all of the sections.

\section{Data Analysis}

Descriptive analysis and Pearson correlation analysis were performed in IBM SPSS Statistics 22.0. Structural equation modeling (SEM) was used to examine the measurement model and mediation models in AMOS Graphics. We tested the structural model using maximum likelihood estimation. A parceling technique was used in order to avoid errors sourcing from one-dimensional measures (Little et al., 2002). Three and two parcels were obtained from the Dating Violence Scale and the Moral Disengagement Scale, respectively.

Several indices of goodness-of-fit were used as criteria for the above model selection. We used $\chi^{2} / \mathrm{df}<5, \mathrm{CFI}$, TLI, GFI, IFI >.90, SRMR and RMSEA <.08, as the assessment standards of the model fit index (Hu \& Bentler 1999; MacCallum et al., 1996; Tabachnick \& Fidell (2007). A bootstrap analysis was conducted in order to determine the mediator role of moral disengagement in the relationship between gender role and dating violence (Preacher \& 
Hayes, 2008). The Bootstrapping Confidence interval was estimated in the indirect impact of gender role on dating violence. 10000 resampling and $95 \%$ confidence intervals were used in this process.

\section{Results}

\section{Descriptive Statistics}

The total scores of all variables in this study are presented in terms of gender. The mean score obtained from gender roles $(\bar{X}: 51.70)$ was lower than the mean score of the female participants $(\bar{X}: 54.09)$, but higher than the score of the male participants $(\bar{X}: 45.28)$. The mean score obtained from moral disengagement $(\bar{X}: 17.70)$ was lower than the mean score of the female participants $(\bar{X}: 16.89)$, but higher than score of the male participants $(\bar{X}: 19.90)$. The mean score obtained from attitudes towards female psychological dating violence $(\bar{X}: 22.38)$ was lower than the mean score of both the female participants $(\bar{X}: 21.43)$, but higher than score of the male participants $(\bar{X}: 24.97)$. The mean score obtained from attitudes towards female physical dating violence $(\bar{X}: 23.63)$ was lower than the mean score of both the female participants $(\bar{X}: 22.86)$, but higher than score of the male participants $(\bar{X}: 25.71)$. The mean score obtained from attitudes towards male psychological dating violence $(\bar{X}: 29.99)$ was lower than the mean score of both the female participants ( $\bar{X}: 27.33)$, but higher than score of the male participants $(\bar{X}: 37.16)$. Similarly, the mean score obtained from attitudes towards male physical dating violence $(\bar{X}: 20.61)$ was lower than the mean score of both the female participants $(\bar{X}: 19.06)$, but higher than score of the male participants $(\bar{X}: 24.80)$.

\section{Preliminary Analyses}

The relationships among gender roles, moral disengagement and dating violence levels of university students were analyzed using structural equation modeling. The analysis was performed in two steps. In the first step, descriptive statistics were determined. In the second step, the hypothesized model was tested. The descriptive statistics and Pearson correlation coefficients are presented in Table 1.

Table 1. Descriptive correlations among study variables

\begin{tabular}{llllllllll}
\hline Variable & 1 & 2 & 3 & 4 & 5 & 6 & 7 & 8 & 9 \\
\hline 1.GRPar1 & - & & & & & & & & \\
2.GRPar2 & $.55^{* *}$ & - & & & & & & & \\
3.GRPar3 & $.61^{* *}$ & $.58^{* *}$ & - & & & & & & \\
4.MDPar1 & $-.34^{* *}$ & $-.43^{* *}$ & $-.39^{* *}$ & - & & & & & \\
5.MDPar2 & $-.16^{* *}$ & $-.26^{* *}$ & $-.30^{* *}$ & $.50^{* *}$ & - & & & & \\
6.FDVpsyc & $-.37^{* *}$ & $-.41^{* *}$ & $-.43^{* *}$ & $.34^{* *}$ & $.28^{* *}$ & - & & & \\
7.FDVphys & $-.26^{* *}$ & $-.32^{* *}$ & $-.36^{* *}$ & $.34^{* *}$ & $.27^{* *}$ & $.62^{* *}$ & - & & \\
8.MDVpsyc & $-.51^{* *}$ & $-.42^{* *}$ & $-.52^{* *}$ & $.35^{* *}$ & $.28^{* *}$ & $.56^{* *}$ & $.48^{* *}$ & - & \\
9.MDVphys & $-.41^{* *}$ & $-.38^{* *}$ & $-.43^{* *}$ & $.39^{* *}$ & $.23^{* *}$ & $.52^{* *}$ & $.55^{* *}$ & $.66^{* *}$ & - \\
M & 17.09 & 16.33 & 18.28 & 9.90 & 7.80 & 22.39 & 23.63 & 29.99 & 20.61 \\
SD & 4.13 & 4.00 & 3.70 & 3.88 & 3.29 & 7.76 & 8.85 & 9.29 & 8.45
\end{tabular}


Note. ${ }^{* *} p<.01$, GRPar gender roles parcels; MDPar moral disengagement parcels; FDVpsyc attitudes towards female psychological dating violence scale; FDVphys, attitudes towards female physical dating violence scale; MDVpsyc attitudes towards male psychological dating violence scale; MDVphys, attitudes towards male physical dating violence scale, $M$ mean, SD standard deviation.

When Table 1 is examined, it can be seen that there is a significant negative correlation between gender roles parcels and moral disengagement parcels $(r=-.16 \leq r \leq-.43, p<.01)$ and between gender roles parcels and dating violence $(r=-.26 \leq r \leq-.52, p<.01)$. Moreover, there was a significant positive correlation between moral disengagement parcels and dating violence $(r=.23 \leq r \leq .39, p<.01)$.

\section{Measurement Model}

First, we tested the measurement model to assess whether each of the latent variables was represented by their indicators. The measurement model consisted of three latent factors, gender roles, moral disengagement and dating violence, and nine observed variables. The measurement model test indicated a satisfactory model fit: $\chi_{(22, N=425)}^{2}=67.112, p<.001$; $\chi^{2} / \mathrm{df}=2.918 ; \mathrm{CFI}=.97 ; \mathrm{TLI}=.96 ; \mathrm{GFI}=.97 ; \mathrm{SRMR}=.034 ; \mathrm{RMSEA}=.06 ;$ C.I. $[.58, .86]$. The factor loadings of all the indicators were significant (ranging from .34 to .74, $\mathrm{p}<.001$ ), demonstrating that respective indicators are true representative of their latent factors.

\section{Mediation Analyses}

In the second phase of the study, the structural equation model was tested in order to determine the mediator role of moral disengagement in the relationship between gender roles and dating violence. The results are presented in Figure 2.

All path coefficients were observed to be significant in the analysis. Gender roles predicted dating violence negatively $(B=-.65, p<.01)$ and moral disengagement negatively $(B=-.58$, $p<.01)$. In addition, moral disengagement predicted dating violence negatively $(B=.17, p<0.01)$. Moreover, the effect coefficient of moral gender roles predicting dating violence through the mediation of moral disengagement was estimated to be -.10.

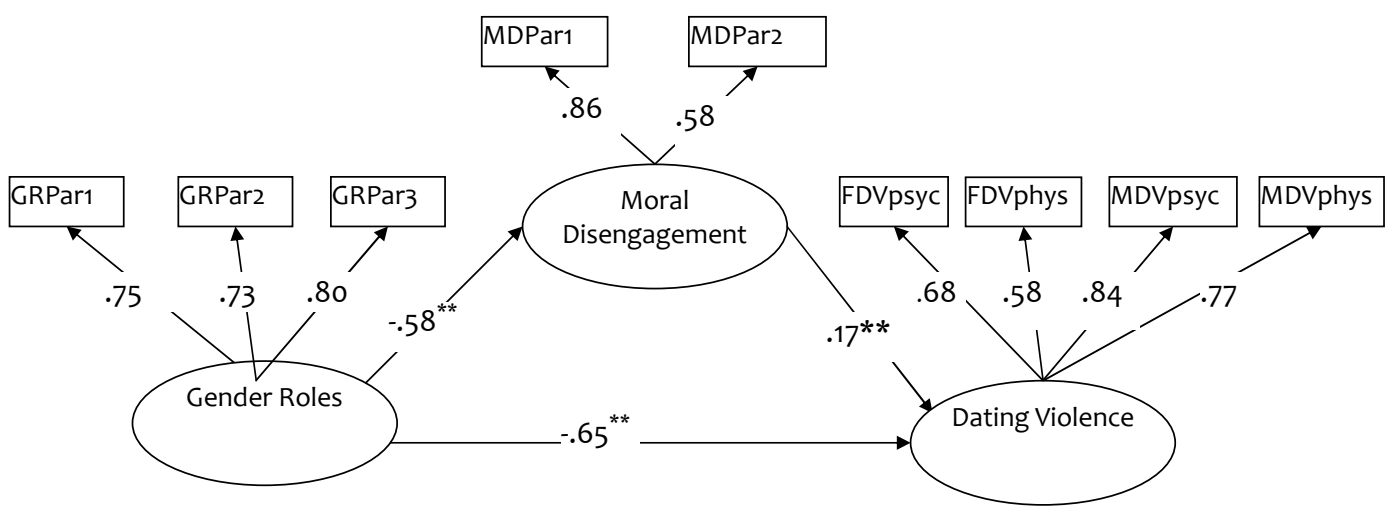

Figure 2. Mediation for moral disengagement on dating violence via gender roles 
When the fit indexes of the model were examined, all of them were found to be at acceptable levels. The fit indexes were as follows: $\chi^{2}{ }_{(22, N=425)}=53.385, p<.001 ; \chi^{2} / \mathrm{df}=2.427 ; \mathrm{GFI}=.97 ; \mathrm{CFI}=$ $.98 ; \mathrm{NFI}=.97 ; \mathrm{TLI}=.97 ; \mathrm{SRMR}=.033 ; \mathrm{RMSEA}=.058$. Therefore, it can be stated that the structural equation model was confirmed.

10,000 resample bootstrapping were conducted in order to provide additional evidence related to the significance of direct and indirect effects. The bootstrapping coefficients and the lower and upper bounds of 95\% confidence intervals are presented in Table 2 .

Table 2. Bootstrapping results

$95 \%$ C. I.

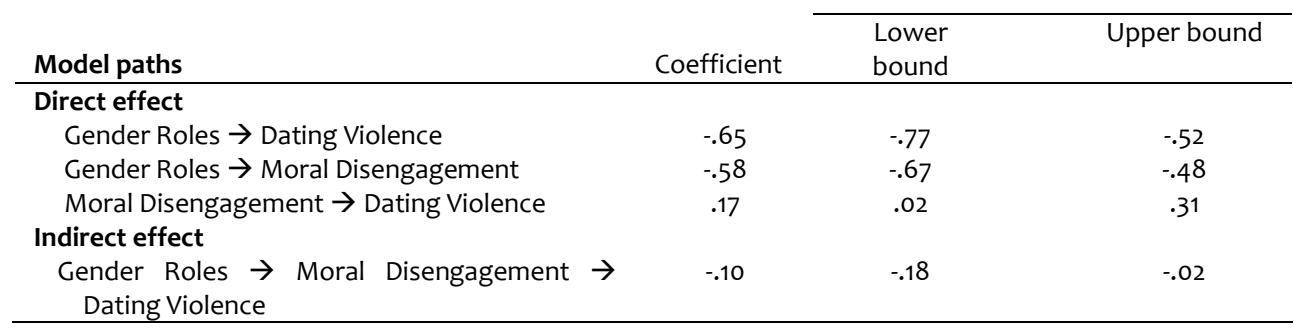

When Table 2 is examined, it can be seen that all of the effects in the structural equation model were significant. The bootstrapping confidence intervals lower and upper bounds of both the direct and indirect effects comprise not zero. Therefore, it can be stated that the university students' gender roles had an effect on their dating violence behaviors through the mediation of moral disengagement according to the bootstrapping results.

\section{Discussion}

Dating violence is a current issue as a social problem. Identifying and eliminating the causes of dating violence is a prerequisite for the happiness of individuals and the welfare of society. In this study, the mediator role of moral disengagement in the relationship between gender roles attitudes and dating violence behaviors of Turkish university students was investigated. As expected, the results showed that the moral disengagement played a mediator role in the relationship between gender roles attitudes and dating violence. Accordingly, gender roles attitude was negatively correlated with moral disengagement and moral disengagement negatively predicted dating violence. In short, it can be expressed that as the university students' moral disengagement level increased, their gender roles egalitarian attitude level decreased and dating violence level increased, and vice versa.

In this research, firstly, the differences of gender roles, moral disengagement, and dating violence in terms of gender were examined. The results showed that male participants' mean scores of moral disengagement and dating violence were higher than the mean scores of women, while males' gender roles attitude mean score was lower than the mean score of women.

The literature involves many studies showing that female had significantly higher gender role attitudes (Berkel, Vandiver, \& Bahner, 2004; Hilton, Harris \& Rice, 2003; Willis, Hallinan, \& Melby, 1996). In these studies, it was found that women were generally more egalitarian than 
men. Considering that traditional methods in child care are preferred more in the dominant culture in Turkey (Kircaali-Iftar, 2005; Hortacsu, Kalaycioglu ve Rittersberger-Tilic, 2003; Buldukoglu ve Kukulu, 2008; Gozutok, Er ve Karacaoglu, 2006; Ahioglu-Lindberg, 2012), it was an expected result that male participants had less egalitarian perception. When the studies on moral disengagement were reviewed, it was observed that males' level of moral disengagement was higher than female (Bandura et al., 1996; McAlister, Bandura, \& Owen, 2006). Therefore, it can be stated that the results of the current study are in parallel with the literature. Considering especially the cultural child care style, it was an expected result that males had higher levels of moral disengagement than females. Dating violence is a relatively novel field of study for Turkish culture. The studies in limited number show that males had significantly more positive perceptions towards dating violence when compared with females (Mercer, 1988; O’Keefe, 1997; Sezer, 2008; Erdem \& Şahin, 2017). The similar finding in the current study shows that the current study not only represented the culture well but also supported the studies resulting that males were more positive towards dating violence.

In this study, a negative relationship was found between gender roles attitude and dating violence. With reference to this finding, it can be stated that undergraduates in the current culture view the dating violence in a more positive way as their egalitarian attitudes decrease. This finding is consistent with the literature (Berkel, Vandiver, \& Bahner, 2004; Forbes et al., 2006; Forbes, Adams-Curtis, \& White, 2004; Glick et al., 2002; Hillier \& Foddy, 1993; Hilton, Harris, \& Rice, 2003; Jenkins \& Aube, 2002; Ryan, 1995; Sigelman, Berry, \& Wiles, 1984). Individuals with traditional gender roles may regard having a say or dominate their partners as a right. Therefore, individuals whose demands are rejected by their partners may prefer to put pressure on the partner, stalk them, or commit violence. On the other hand, individuals with an egalitarian viewpoint care for the needs of their partner and pay attention to the happiness of them. Considering that undergraduates especially in Turkey have traditional gender roles (Celik et al., 2013; Vefikulucay et al., 2007), it can be stated that it is inevitable to view it as a right to commit violence against the partner.

Another finding obtained in this study was that there was a positive relationship between gender roles attitude and moral disengagement. Individuals with traditional gender roles see no harm to put pressure on their partners. Individuals who put pressure on their partners prefer to adapt their judgement to their moral standards cognitively. Especially in patriarchal societies, men already see women at a lower status. They argue that women incite them and deserve inhuman treatment as an excuse for their violence against women and believe it cognitively (Bandura, 1991; 2002). Considering that the social structure is traditional, it can be seen that this behavior is accepted by the social environment. Thus, it can be observed that individuals with moral disengagement create moral standards that are accepted by themselves and their environment and they maintain their traditional gender roles.

As a final note, this study found that moral disengagement mediated between gender roles attitude and dating violence. A body of research suggested the relationship between gender roles and dating violence (Berkel, Vandiver, \& Bahner, 2004; Brown, Sumner, \& Nocera, 2002; Coleman \& Stith 1997; Follingstad et al., 1988; Forbes et al., 2006; Hillier \& Foddy, 1993; Hilton, Harris, \& Rice, 2003; Taylor \& Sorenson, 2005). When the results of these studies are reviewed holistically, it can be expressed that individuals with traditional gender roles had a tendency to accept dating violence and they were either violence victim or committed violence. However, the literature involves evidence regarding the relationship between moral disengagement and violence (Bandura, Caprara, \& Zsolnai, 2000; Bandura et al., 1996, 2001, 2002, 2017; Caprara et 
al., 1996; Elliott \& Rhinehart, 1995; Gini, 2006; Menesini et al., 2003; Hyde, Shaw, \& Moilanen, 2010; Paciello et al., 2008; Pepler et al., 2008). Experience of moral disengagement causes individuals to accept dating violence, approve violence against themselves, and perceive violence as a solution tool for interpersonal problems. Another proof for this notion is Bandura's (1990) opinions regarding the relationship between moral disengagement and gender roles. Individuals with traditional gender roles not only have a say on their partners, tell them what to do, humiliate, regard them as second-class but also believe that this is what needs to be done and what the moral thing is. Therefore, traditional gender roles might be affecting moral disengagement, which in turn increases acceptive attitude towards dating violence. In a similar manner, egalitarian gender roles might be decreasing the acceptance level of dating violence by decreasing the moral disengagement.

The participants of this study were undergraduates. Considering the age period of undergraduates, it can be seen that they are in young adulthood. In this period, the developmental tasks are to find a job and prepare for marriage (Santrock, 2011; 2014). It is seen that individuals build their first satisfactory relationship with the opposite sex during the preparation for marriage. In this first relationship with the partner, looking after his/her rights, having equal roles in making decisions about life, and sharing responsibility will enable individuals to be happy and fulfill the developmental task with a success. However, in a situation in which one of the partners is more dominant in the relationship, it will be inevitable for the partner who feels under pressure to be unhappy.

\section{Limitations}

Certain limitations are evident in the current study. First of all, the responses of participants may include social desirability biases, since the data was collected using self-reported measures. The study sample includes only a limited number of schools in terms of variety. Therefore, the findings of the study should not be generalized as being typical of all university students. Additionally, the findings are related to a general sample, and the behaviors of the male and female participants were not examined separately. It is recommended that more detailed information, using qualitative or other research methods, is obtained in future studies, and that the data obtained is investigated in terms of gender and age variables.

\section{Conclusion}

The main result of the study is identifying the mediator role of moral disengagement in the relationship between gender roles attitudes and dating violence. Considering that the findings are consistent with the literature (Berkel, Vandiver, \& Bahner, 2004; Forbes et al., 2006; Forbes, Adams-Curtis, \& White, 2004; Glick et al., 2002) and that gender roles had an affirmative effect on dating violence, it becomes clear that universities and other shareholders should organize education so that the individuals and especially undergraduates would obtain an egalitarian understanding. Considering that undergraduates in Turkey had traditional gender roles (Celik et al., 2013; Vefikulucay et al., 2007), undergraduates who are still studying at university should be informed and educated by universities and non-governmental organizations. Although the data collection tools used in this study did not measure committing level of dating violence, remaining silent in case of an existent violence is an important factor in terms of dissemination of violence (Rabbani, Qureshi, Rizvi, 2008). The partial mediator role determined in the model of this study is an evidence for that situation. Prediction of dating violence by the gender roles at a significant level maintained after the 
moral disengagement was included in the model. Therefore, adapting egalitarian gender roles would be an important step in diminishing the dating violence. Within this framework, although decreasing sexist viewpoint to decrease the affirmative attitude towards dating violence might be effective, it would not be enough by itself. At the same time, efforts to support moral development of individuals should be encouraged.

\section{Compliance with Ethical Standards}

\section{Conflict of Interest}

Both authors declare that they have no conflict of interest.

\section{Ethical Approval}

All procedures performed in the studies involving human participants were in accordance with the ethical standards of the institutional and/or national research committee and with the 1964 Helsinki Declaration and its later amendments or with comparable ethical standards.

\section{Informed Consent}

Informed consent was obtained from all individual participants included in the study.

\section{References:}

Ahioglu-Lindberg, E. N. (2012). Cocuk Yetistirme Acisindan Turkiye'de Cocuklugun Tarihi. Pamukkale Universitesi Egitim Fakultesi Dergisi, 31(31), 41-52.

Amato, P. R., \& Booth, A. (1995). Changes in gender role attitudes and perceived marital quality. American Sociological Review, 60, 58-66.

Angelone, D. J., Mitchell, D., \& Lucente, L. (2012). Predicting perceptions of date rape: An examination of perpetrator motivation, relationship length, and gender role beliefs. Journal of Interpersonal Violence, 27, 2582-2602.

Bakioglu, F. \& Turkum, A. S. (in press). Adaptation of Gender Role Attitude Scale to Turkish: A Study of Validity and Reliability. Kastamonu Education Journal.

Bandura, A. (1990). Selective activation and disengagement of moral control. Journal of Social Issues, 46(1), 27-46.

Bandura, A. (1991). Social cognitive theory of moral thought and action. Icinde W. M. Kurtines \& J.L., Gewirtz (editorler). Handbook of moral behavior and development: theory, research and applications, (pp. 71-129). Hillsdale, New Jersey: Lawrence Erlbaum Associates.

Bandura, A. (2002). Selective moral disengagement in the exercise of moral agency. Journal of Moral Education, 31(2), 101-119.

Bandura, A., Barbaranelli, C., Caprara, G. V., \& Pastorelli, C. (1996). Mechanism of moral disengagement in the exercise of moral agency. Journal of Personality and Social Psychology, 71, 364-374.

Bandura, A., Caprara, G. V., \& Zsolnai, L. (2000). Corporate transgressions through moral disengagement. Journal of Human Values, 6, 57-64. 
Bandura, A., Caprara, G. V., Barbaranelli, C., Pastorelli, C., \& Regalia, C. (2001). Sociocognitive self-regulatory mechanisms governing transgressive behavior. Journal of Personality and Social Psychology, 80, 125-135.

Berkel, L., Vandiver, B. \& Bahner, A. (2004). Gender Role Attitudes, Religion, and Spirituality As Predictors of Domestic Violence Attitudes In White College Students. Journal of College Student Development, 45, 119-133.

Bouffard, L. A. (2010). Exploring the utility of entitlement in understanding sexual aggression. Journal of Criminal Justice, 38, 870-879.

Breiding, M. J., Chen, J., \& Black, M. C. (2014). Intimate partner violence in the United States2010. Atlanta, GA: National Center for Injury Prevention and Control, Centers for Disease Control and Prevention.

Brown, T. J., Sumner, K. E., \& Nocera, R. (2002). Understanding sexual aggression against women: An examination of the role of men's athletic participation and related variables. Journal of Interpersonal Violence, 17(9), 937-952.

Buldukoglu, K. \& Kukulu, K. (2008). Maternal punishment practices in a rural area of Turkey. Child: Care, Health and Development, 34 (2), 180-184

Caetano, R., Schafer, J., Clark, C. L., Cunradi, C. B., \& Raspberry, K. (2000). Intimate partner violence, acculturation, and alcohol consumption among Hispanic couples in the United States. Journal of Interpersonal Violence, 15, 30-45.

Caprara, G. V., Bandura, A., Barbaranelli, C., \& Vicino, S. (1996). La Misura del Disimpegno morale[The assessment of moral disengagement]. Rassegna di Psicologia, 13, 93-105.

Celik, A.S., Pasinlioglu, T., Tan, G., \& Koyuncu, H. (2013). Universite ogrencilerinin cinsiyet esitligi tutumlarinin belirlenmesi, Florence Nightingale Hemsirelik Dergisi, 21 (3), 181186.

Centers for Disease Control and Prevention (2014). Intimate partner violence: Risk and protective factors. Retrieved January 26, 2015 from http://www.cdc.gov/violenceprevention/intimatepartnerviolence/riskprotectivefacto rs.html

Coleman, J. U., \& Stith, S. M. (1997). Nursing students' attitudes toward victims of domestic violence as predicted by selected individual and relationship variables. Journal of Family Violence, 12(2), 113-138.

Elliott, D. S., \& Rhinehart, M. (1995). Moral disengagement, delinquent peers and delinquent behaviour. Unpublished manuscript, University of Colorado, Institute of Behavioral Science.

Erbas, E., \& Sahin-Percin, N. (2017). Validation of moral disengagement scale in turkish and its relationship with personenvironment fit. AIBU Sosyal Bilimler Enstitusu Dergisi, 1,17, 177-190.

Erdem, A., \& Sahin, R. (2017). Undergraduates' Attitudes toward Dating Violence: Its Relationship with Sexism and Narcissism. International Journal of Higher Education, 6(6), 91-105.

Erdem, Tunc, \& Erdem (2018). Cyber Dating Violence Inventory: Validity And Reliability Study (Öz). 2oth International Congress on Psychological Counseling and Guidance, 19 Mayıs University, Samsun. https://2018.pdrkongreleri.org/dosyalar/files/pdrkongre2018_ozetler.pdf

Follingstad, D. R., Rutledge, L. L., Polek, D. S., \& McNeill-Hawkins, K. (1988). Factors associated with patterns of dating violence toward college women. Journal of Family Violence, 3(3), 169-182.

Forbes, G. B., Adams-Curtis, L. E., \& White, K. B. (2004). First-and second-generation measures of sexism, rape myths and related beliefs, and hostility toward women: Their 
interrelationships and association with college students' experiences with dating aggression and sexual coercion. Violence Against Women, 10(3), 236-261.

Forbes, G. B., Adams-Curtis, L. E., Pakalka, A. H., \& White, K. B. (2006). Dating aggression, sexual coercion, and aggression-supporting attitudes among college men as a function of participation in aggressive high school sports. Violence Against Women, 12(5), 441-455.

Garcia-Cueto, E., Rodriguez-Diaz, F.J., Bringas-Molleda, C., Lopez-Cepero, J., Paino-Quesada, S. \& Rodriguez-Franco, L. (2015). Development of the Gender Role Attitudes Scale (GRAS) amongst young Spanish people. International Journal of Clinical and Health Psychology, 15(1), 61-68.

Gini, G. (2006). Social cognition and moral cognition in bullying: What's wrong? Aggressive Behavior, 32, 528-539.

Glick, P., Sakalli-Ugurlu, N., Ferreira, M. C., \& Aguiar de Souza, M. (2002). Ambivalent sexism and attitudes toward wife abuse in Turkey and Brazil. Psychology of Women Quarterly, 26(4), 292-297.

Gozutok, F.D, Er, K.O, Karacaoglu, C. (2006). Okulda Dayak (1992 ve 2006 Yillari Karsilastirmasi). Bilim ve Aklin Aydınliginda Egitim, Sayi:75.

Hillier, L., \& Foddy, M. (1993). The role of observer attitudes in judgments of blame in cases of wife assault. Sex Roles, 29(9), 629-644.

Hilton, N., Harris, G. \& Rice, M. (2003). Adolescents' Perceptions of The Seriousness Of Sexual Aggression: Influence of Gender, Traditional Attitudes, and Self-Reported Experience. Sexual Abuse. A Journal of Research and Treatment 15(3), 201-214.

Hortacsu, N., Kalaycioglu, S., Rittersberger-Tilic, H. (2003). Intrafamily aggression in Turkey: Frequency, Instigation, and Acceptance. The Journal of Social Psychology, 143(2), 163184.

Hu, L.T., \& Bentler, P.M. (1999). Cutoff criteria for fit indexes in covariance structure analysis: conventional criteria versus new alternatives. Structural Equation Modeling: $A$ Multidisciplinary Journal, 6(1), 1-55.

Hyde, L. W., Shaw, D. S., \& Moilanen, K. L. (2010). Developmental precursors of moral disengagement and the role of moral disengagement in the development of antisocial behavior. Journal of abnormal child psychology, 38(2), 197-209.

Jakupcak, M., Lisak, D., \& Roemer, L. (2002). The role of masculine ideology and masculine gender role stress in men's perpetration of relationship violence. Psychology of Men \& Masculinity, 3, 97-106.

Jenkins, S.S., \& Aube, J. (2002). Gender differences and gender-related constructs in dating aggression. Personality and Social Psychology Bulletin, 28(8), 1106-1118.

King, L.A., \& King, D.W. (1990). Abbreviated measures of sex-role egalitarian attitudes. Sex Roles, 23, 659-673.

Kircaali-Iftar, G. (2005). How do Turkish mothers discipline children? An analysis from a behavioural perspective. Child: Care, Health and Development, 31,(2) 193-201.

Little, T.D., Cunningham, W.A., Shahar, G., \& Widaman, K.F. (2002). To parcel or not to parcel: Exploring the question, weighing the merits. Structural equation modeling, 9(2), 151173.

MacCallum, R.C., Browne, M.W., \& Sugawara, H.M. (1996). Power analysis \& determination of sample size for covariance structure modeling. Psychological Methods, 1(2), 130-149. doi:10.1037/1082989X.1.2.130

McAlister, A. L., Bandura, A., \& Owen, S. V. (2006). Mechanisms of moral disengagement in support of military force: The impact of Sept. 11. Journal of Social and Clinical Psychology, 25(2), 141-165. 
McHugh, M. C., \& Frieze, I. H. (1997). The measurement of gender-role attitudes a review and commentary. Psychology of Women Quarterly, 21(1), 1-16.

Menesini, E., Sanchez, V., Fonzi, A., Ortega, R., Costabile, A., \& Lo Feudo, G. (2003). Moral emotions and bullying: A cross-national comparison of differences between bullies, victims and outsiders. Aggressive Behavior, 29, 515-530.

Mercer, S. (1988). Not a pretty picture: An exploratory study of violence against women in high school dating relationships. Resources for Feminist Research, 17, 15-25.

Moore, Celia, Detert, James R., Trevino, Linda K., Baker, Vicki L., \& Mayer, David M. (2011). "Why Employees Do Bad Things: Moral Disengagement and Unethical Organizational Behavior". Personnel Psychology 65, 1-48.

Morelli, M., Bianchi, D., Chirumbolo, A., \& Baiocco, R. (2018). The cyber dating violence inventory. Validation of a new scale for online perpetration and victimization among dating partners. European Journal of Developmental Psychology, 15(4), 464-471.

Niolon, P. H., Kearns, M., Dills, J., Rambo, K., Irving, S., Armstead, T., \& Gilbert, L. (2017). Preventing intimate partner violence across the lifespan: A technical package of programs, policies, and practices. Atlanta, GA: National Center for Injury Prevention and Control, Centers for Disease Control and Prevention.

O'Keefe, M. (1997). Predictors of dating violence among high school students. Journal of Interpersonal Violence, 12, 546-568.

Paciello, M., Fida, R., Tramontano, C., Lupinetti, C., \& Caprara, G. V. (2008). Stability and change of moral disengagement and its impact on aggression and violence in late adolescence. Child Development, 79(5), 1288-1309.

Pepler, D., Jiang, D., Craig, W., \& Connolly, J. (2008). Developmental trajectories of bullying and associated factors. Child Development, 79, 325-338.

Preacher, K.J., \& Hayes, A.F. (2008). Contemporary approaches to assessing mediation in communication research. The Sage sourcebook of advanced data analysis methods for communication research, 13-54. doi:10.4135/9781452272054.n2.

Price, E.L; Byers, E.S; Dating Violence Research Team. (1999). The attitudes towards dating violence scales: development and initial validation. Journal of Family Violence, 14, ;0.4,19, 351-375.

Rabbani F., Qureshi F., Rizvi, N. (2008) Perspectives on Domestic Violence: Case Study from Karachi, Pakistan [Elektronik Surum]. Eastern Mediterranean Health Journal, 14 (2), 415-426.

Reyes, H. L. M., Foshee, V. A., Niolon, P. H., Reidy, D. E., \& Hall, J. E. (2016). Gender role attitudes and male adolescent dating violence perpetration: Normative beliefs as moderators. Journal of youth and adolescence, 45(2), 350-360.

Ryan, K. (1995). Do Courtship-Violent Men Have Characteristics Associated With A“Battering Personality?" Journal of Family Violence, 10, 99-120.

Santrock, J. W. (2011). Yasam boyu gelisim (Cev. ed. Galip Yuksel). Ankara: Nobel Yayin Dagitim.

Santrock, J. W. (2014). Ergenlik (Cev. ed. Didem Muge Siyez). Ankara: Nobel Akademik Yayincilik.

Sezer, O. (2008). The adaptation of acceptance of couple violence scale into Turkish: Validity and reliability studies. Journal of the Faculty of Education, 9(16), 1-15.

Sigelman, C., Berry, C. \& Wiles, K. (1984). Violence in College Students' Dating Relationships. Journal of Applied Social Psychology, 14, 530-548.

Tabachnick, B.G., \& Fidell, L.S. (2007). Using multivariate statistics. Boston: Pearson. 
Taylor, C. A., \& Sorenson, S. B. (2005). Community-based norms about intimate partner violence: Putting attributions of fault and responsibility into context. Sex Roles, 53(78), 573.

Turan, N., Ozturk, A., Kaya, H., \& Asti, T.A. (2011). Gender and Nursing. Maltepe University Journal of Nursing Science and Art, 4 (1), 167-173.

Turkiye Istatistik Kurumu (2008). Nufus, Konut ve Demografi: Aile Yapisi. Subat 2008, Mevcut Adres: http://www.turkstat.gov.tr/VeriBilgi.do?tb_id=64\&ust_id=11.

Willis, C., Hallinan, M.\& Melby, J. (1996). Effects of Sex Role Stereotyping Among European American Students on Domestic Violence Culpability Attributions. Sex Roles, 34, 475491.

Yumusak, A., \& Sahin, R. (2014). The validity and reliability of Attitudes Towards Dating Violence Scales, Electronic Journal of Social Sciences, 13(49), 233-252.

\section{Biographical notes:}

Ahmet ERDEM is an assistant professor of psychological counseling and guidance at the Faculty of Education, Tokat Gaziosmanpaşa University, Tokat, Turkey. He holds a PhD in psychological counseling and guidance from Tokat Gaziosmanpaşa University. His research interests include psychological counseling and guidance, datin violence, problematic internet usage, wisdom, online counseling, and gender roles.

Fuad Bakioğlu is an assistant professor of psychological counseling and guidance at the Faculty of Education, Karamanoğlu Mehmetbey University, Karaman, Turkey. He holds a PhD in psychological counseling and guidance from Anadolu University. His research interests include psychological counseling and guidance, gender roles, cyber bullying, moral disengagement, multicultural counseling, and internet addiction. 